\title{
The Age of Toxicity: The Influence of Gender Roles and Toxic Masculinity in Harmful Heterosexual Relationship Behaviours
}

\author{
Hazel Gray ${ }^{1}$
}

\begin{abstract}
Although heterosexual relationships have been evolving since the dawn of humanity, there continues to be a considerable amount of inequality, toxicity, and dissatisfaction within heterosexual couplings. This paper explores the ways in which socially prescribed gender roles and toxic masculinity contribute to behaviours which lead to toxicity and unhappiness in heterosexual relationships. The behaviours that this paper will discuss include coercive control as well as physical and sexual violence, all of which are behaviours that according to current literature, are shockingly common in heterosexual relationships. Moreover, the present paper will investigate previous literature in order to explore these concepts in depth through theoretical concepts as well as previous qualitative and quantitative studies done on heterosexual relationship satisfaction. This particular research paper aims to identify and define the concepts of socially prescribed gender roles and toxic masculinity, before applying these concepts to the previously mentioned relationship behaviours in order to determine just how these social concepts contribute to or cause these behaviours in heterosexual couplings.
\end{abstract}

\footnotetext{
${ }^{1}$ MacEwan University
} 


\section{Introduction}

Despite the fact that feminist and civil rights movements have been working toward gender equality for nearly a century, toxic masculinity and misogynistic gender norms still run rampant in our society's institutions (Wilchins, 2019, p. 5). These products of the patriarchal belief systems which have dominated history are constantly being ingrained into the minds of individuals, resulting in behaviours which further sustain these patriarchal systems, thus creating a vicious cycle of inequality (Wilchins, 2019, p. 18). It is because of this cycle of inequality that sociological studies must undertake the task of exploring how and why these societal ills occur, and to then formulate potential ways for our society to heal and overcome these problems. This is why the present research paper aims to explore the ways in which gender norms and toxic masculinity negatively influence the behaviour of heterosexual couples. In particular, I will be exploring the ways in which toxic masculinity and gender norms manifest themselves in heterosexual relationships through problems such as coercive control and physical and sexual violence.

In order to explore the previously mentioned themes, this paper will investigate and analyze the existing literature on each individual topic; this particular subject of toxic masculinity, gender norms, and their roles in maladaptive heterosexual relationship behaviours requires an in-depth look at the social institutions which contribute to these issues before they can be applied to the real-life problems of heterosexual couples. First, some existing literature on this topic will be studied in depth in order to provide a theoretical framework to this paper's specific topic before diving into the specific issues themselves. Following this review of literature, the concepts of toxic masculinity and society's existing gender roles will be fleshed out individually in detail. The gender roles that are in place in our current society have been operating for centuries in order to subjugate and control women (Paynter \& Leaper, 2016, p. 395). However, these same gender roles have backfired due to the fact that they no longer only oppress women, but rather they oppress any gendered body. One way that gender roles have evolved to express further oppressive forces is toxic masculinity; this form of masculinity which discourages men from displaying emotion or behaving effeminately has reinforced the outdated gender roles and stereotypes that we have already suffered under for centuries, demonstrating our society's desperate need for reform when it comes to gendered norms, moralities, and sanctions. This sociological need for reform is what inspires the purpose of the present research paper, therefore I hypothesize that both men and women will exhibit traits of toxic masculinity and gender roles, and that these traits will correlate positively with bad relationship behaviours including coercive control, physical abuse, sexual violence, or any combination of these behaviours.

\section{Literature Review}

In order to fully comprehend and analyze the topics of this paper, we must first look at each aspect of the research question individually as well as in relation to one another. Scholars in the past (e.g., Gidney, 2007, Waling, 2019, and Abbot et al., 2020) have individually observed the concept of toxic masculinity, the existing gender roles that are upheld by society, as well as the ways in which individuals view unhealthy conduct in heterosexual relationships. However, these same scholars rarely look at how the former two concepts interact with one another in order to 
contribute to the latter. Therefore, I will be observing gendered norms and applying them to the current literature in order to demonstrate how widespread, macro social concepts contribute to micro interactions individuals have in their everyday lives within intimate heterosexual relationships. My research will focus on the ways in which toxic masculinity and gender roles manifest themselves through harmful behaviour practices within relationships, according to previous research.

In her article, "Dating and Gating: The Moral Regulation of Men and Women at Victoria and University Colleges, University of Toronto, 1920-60" (2007), Catherine Gidney observes the ways in which university residences have upheld and sustained outdated gender roles through their overall culture and the student's interactions with one another in a period which begins in the 1920s, and ends in the 1960s (Gidney, 2007, p. 138). Gidney commences her discussion by considering the differences between the regulations of the University of Toronto's male and female residences in 1935; she discusses how women's dormitories are far stricter in their regulations than men's dormitories, shown in the fact that female residents were required to have a chaperone if they were attending an event which would include any number of men, and were obligated to obtain permission before leaving the residences at night, whereas male residents could come and go as they pleased (Gidney, 2007, p. 138-139). Gidney mentions these regulations for the same reason that they are mentioned in the present research paper; they demonstrate the ways in which gender roles and norms have operated in everyday life over time, and they show how women have been victimized by gender roles throughout Canadian academic history. Following her mention of the regulations that were in place almost a whole century ago in 1935, she goes on to discuss the reasons why regulations were so extreme; she states that the parents and educators of female students believed that these student's morality needed to be regulated according to the dominant standard at the time, which was the standard of the Christian middle-class (Gidney, 2007, p. 141). Gidney's study asserts the fact that many institutions, including universities and their residences, reinforced outdated gender norms which were originally created in order to control and subjugate women, while simultaneously allowing men to do as they pleased in order to uphold Christian beliefs on morality. This is especially alarming when one considers the fact that these gender norms which existed almost a century ago continue to impact the lives of individuals today; the gender norms and morals that Gidney discusses in her article are ones that continue to influence modern men and women in all societal institutions, including heterosexual relationships.

In her article, 'Problematising 'Toxic' and 'Healthy' Masculinity for Addressing Gender Inequalities" (2019), Andrea Waling compares and contrasts the concepts of toxic and healthy masculinities as they are described in discourses surrounding gender inequality. In her article, she describes toxic masculinity as the unhealthy practices of masculinity which have resulted in the oppressions that men, women, and gender diverse individuals have lived under for centuries (Waling, 2019, p. 365), a concept that will be delved into in more detail later on in this research paper. Waling goes on to contrast this concept of toxic masculinity with another concept of "healthy masculinity" (Waling, 2019, p. 362-375); she describes this notion of masculinity as a positive or progressive form of masculinity which is used to teach men and boys how to behave responsibly as masculine bodies, a concept which asks men to be more engaged with their emotional selves, especially in regard to female partners (Waling, 2019, p. 367). These two notions of masculinity as introduced by Waling demonstrate the established ways in which males identify 
themselves and their behaviour, and the underlying values that determine the way men interact with women, particularly when it comes to intimate heterosexual relationships. However, Waling goes on to criticize both of these labels as reinforcers of gender inequality; she argues that the labels of 'toxic' and 'healthy' masculinities imply that the maladaptive behaviours associated with toxic masculinity are not conscious choices that these men make, but an illness that they contract, and that they are the cause of gender inequality, rather than a product of it. (Waling, 2019, p. 368). Waling's work is especially relevant to this paper's topic as it provides a theoretical background to the concept of toxic masculinity, and critically examines the concepts of toxic and healthy masculinity in order to explain how these concepts contribute further to gender inequality.

The last article that will be explored in this section of the research paper is Abbot, Weckesser, and Egan's “'Everyone knows someone in an unhealthy relationship': young people's talk about intimate heterosexual relationships in England" (2020). This article observes how young people in England have come to normalize intimate partner violence and coercive control in their heterosexual relationships. This article provides a theoretical context to the topic that is being explored in this research paper, due to the fact that it explores the ways in which young people have come to standardize certain unhealthy relationship behaviours in heterosexual couplings. In their study, Abbot et al. used thirteen focus groups to ask eighty-five young people between the ages of thirteen and eighteen about their experiences with heterosexual relationship dynamics. What their study found was that the participating young people reported dating practices as ambiguous, uncertain, and competitive, that the teens' responses very clearly reflected and sustained traditional gender double standards, and that they justified unhealthy dating practices. The participant's responses reflected gender double standards in the fact that many of them were eager to label girls cheating as calculated, purposeful, and deceitful, whereas boys cheating was expected. Furthermore, the girls of the study stated that they viewed their dating practices as competitive; they labeled themselves as competitors with one another for boys' affection, describing the regularity for girls to "completely change themselves [to] be a completely different character just so they can be with a boy" (Abbot et al., 2020, p. 7). When it comes to justifying unhealthy relationship practices, the study's findings stated that participants spoke openly about both their own domineering behaviours and those of others; they associated jealousy with strength of feeling, meaning that they believed a partner's jealousy and possessiveness, especially in the case of boys, signified how much that person liked them (Abbot et al., 2020, p. 9). What's more, when participants did discuss possessiveness and jealousy in a negative light, they focused more on these traits in girls, and when discussing boys' jealousy negatively, they did it in more of a humorous tone, further normalising unhealthy relationship practices (Abbot et al., 2020, p. 9). The findings of this study perfectly exemplify the ways in which the subjects of the previous literature, gender norms and toxic masculinity, manifest themselves in heterosexual dating practices, therefore providing a contextual illustration of the topics observed in this research paper.

\section{Gender Roles}

Gender roles are just one result of the patriarchy that has dominated Western society throughout history, but its repercussions on the lives of gendered bodies are immense. Authors Paynter and Leaper's article (2016) discusses the potential origins of gender roles and norms when 
they bring up a point on how religious affiliation is often associated with more traditional our outdated beliefs on gender roles (p. 395). They expand on this point by discussing the fact that in many religions, including Christianity, Judaism, and Islam, women are viewed as subordinate and only men are permitted to lead in any and all institutions (Paynter \& Leaper, 2016, p. 395). Additionally, political conservatism is another social institution which often perpetuates and upholds outdated gender roles; as stated by Paynter and Leaper, political conservatism is most often focused on maintaining current institutions and power relations which, in a Western context, includes male dominance and heteronormativity (Paynter \& Leaper, 2016, p. 395). The traditional and outdated beliefs of many religious institutions inspire conservative politics to uphold and preserve these ideals which were originally formulated to subjugate women and perpetuate male dominance (Paynter \& Leaper, 2016); these two forces combined have added up to a society where gender roles are so ingrained into individual minds that they impact us on levels we often do not even notice until it is too late.

Catherine Gidney's study exemplifies the points made in Paynter and Leaper's article when she discusses the fact that the residences she observed featured morals and dynamics that are often found in middle-class Christian families. Gidney's study perfectly exemplifies the ways in which gender norms operate on a daily basis; for example, she states that there is little information available on the regulations for men's residences due to the fact that there was "less social preoccupation" with the men's lifestyles (Gidney, 2007, p. 141-142). This fact, added to the abundance of regulations present in the women's residences that Gidney mentions in her writing simply demonstrate the extent to which gender roles and expectations impact the daily lives of women. Paynter and Leaper also discuss the ways in which gender roles impact women on a daily basis; in particular, they discuss the double standards that are present in dating practices amongst undergraduate men and women. The authors define double standards as what occurs when "values regarding appropriate behaviour are applied differently to groups based on their status" (Paynter \& Leaper, 2016, p. 393); double standards are another subcategory of gender norms which dictate what is acceptable and not acceptable for men and women. However, gender roles and double standards do not only negatively impact women.

Contrary to popular belief, men can also become victims of gender norms. In their article, Catherine A. Emihovich, Eugene L. Gaier and Noreen C. Cronin (1984) observe the ways in which fathers respond to changing norms and sex roles, as well as how they then set expectations for their own sons. During the time in which this article was written, it was considered clinically deviant for men to exhibit more "feminine" behaviour (Emihovich et al., 1984, p. 861), whereas women had already started to exhibit more masculine traits in the slow transition toward a more androgynous society (Emihovich et al., 1984, p. 861). Here, a clear double standard for men is visible; also applicable to today's society, women who possess more masculine traits are more likely to be accepted or praised than men who exhibit more feminine traits, while males who exhibit feminine traits are more likely to experience discrimination, and even violence (Hoskin, 2019 , p. 686). Clearly, gendered norms no longer exist solely to subjugate women; both men and women have become pawns in the chessboard of gendered roles and norms, suffering as a result of gendered roles which were created by oppressive leaders in order to subjugate and control gendered bodies. 
Now that it has been established that both men and women suffer at the hands of specific gender roles, we must observe the ways in which gender roles manifest themselves in heterosexual relationships. In their article, "Emerging Adults' Expectations and Preferences For Gender Role Arrangements in Long-Term Heterosexual Relationships" (2016), Tamara G. Coon Sells and Lawrence Ganong mention five different types of gender role relationships; first, the male head and female complement, which constitutes the typical representation of heterosexual relationships in which the man is the breadwinner and the woman is responsible for household duties and childrearing (Coon Sells \& Ganong, 2016, p. 126). Second is the male senior and female junior relationship dynamic, where both parties have a career, but the man's is viewed as more significant than the woman's, and the woman takes on the lion's share of household duties (Coon Sells \& Ganong, 2016, p. 126). Third is the partner-equal dynamic, where gender roles are interchangeable between the couple (Coon Sells \& Ganong, 2016, p. 126). Fourth, the female senior and male junior, which can be described as the opposite of the male senior and female junior dynamic. Finally, the fifth and last gender role-defined relationship type is the female head and male complement, which is the opposite of the male head and female complement dynamic. According to the article, the egalitarian, dual-career dynamic is the most desirable and is projected to be the most satisfying relationship type (Coon Sells \& Ganong, 2016, p. 125). However, what's obvious at this point is the fact that not every relationship adheres to this dynamic, or this research paper as well as the articles mentioned within it would not exist. On a surface level, gender roles manifest themselves in heterosexual relationships through the division of responsibility and duties, however, this paper will also elaborate on the ways in which gender roles manifest themselves through specific behaviours, as well as how they cause problems in relationships later on. Next, this research paper will observe the ways in which gender roles can be transformed into a whole other beast, known as toxic masculinity, before diving into the ways in which these concepts translate into heterosexual relationship problems.

\section{Toxic Masculinity}

Toxic masculinity is a concept that has haunted both men and women for centuries, causing a myriad of oppressive and entitled behaviour in men, and potentially causing serious harm to others (Hall, 2019, p. 105). As previously mentioned, Andrea Waling's description of toxic masculinity dictates that this concept consists of the unhealthy practices of masculinity, practices which are supposedly responsible for predatory and aggressive heterosexual behaviour, often resulting in domestic violence (Waling, 366). The concept of toxic masculinity goes hand in hand with the concept of male privilege, a term coined by the Duluth Model's power and control wheel (Hall, 2019, p. 105); as described by Christopher Hall (2019), male privilege includes behaviours such as treating the significant other like a servant, making all decisions, acting like the master of the house, and defining gender roles within the relationship (p. 105). As demonstrated by this description, toxic masculinity, male privilege, and gender roles are intimately intertwined with one another; what's more, is that toxic masculinity can find its origins in the same historical context in which gender roles originated. According to scholars (Connell \& Messerschmidt, 2005), toxic masculinity developed as a result of society's male hegemony which dictated that males, males of 
high status in particular, were at the top of the hierarchy in class relations resulting in unequal power dynamics which favoured high status "manly" males (Connell \& Messerschmidt, 2005, p. 831). Toxic masculinity and gender roles are each results of the patriarchal society in which we, Western society, have lived for centuries; these two concepts are both deeply ingrained in our society's norms and values, influencing individual citizens to engage in behaviours which further support this patriarchy in order to preserve the subjugation of women, men, and any other gendered body within its sphere of influence.

So, what exactly does toxic masculinity look like? Scholars (Waling, 2019 \& Wilchins, 2019) have described different behaviours in which toxic masculinity often manifests itself; these include domestic violence, the suppression of men's emotions leading to mental illnesses such as depression and anxiety, men's engagement with physical and political violence, homophobia, engagement in men's rights activism (Waling, 2019, p. 366), less likelihood of seeking medical care, fewer intimate relationships, stronger belief in pregnancy validating manhood, and weaker belief in male responsibility to prevent pregnancy (Wilchins, 2019, p. 6), to name a few. These behaviours are just the tip of the iceberg when it comes to behaviours that are a product of toxic masculinity, and although these behaviours appear to operate on a micro level, they also function on a macro level in order to uphold values of male dominance and power. For example, since the inauguration of former United States president Donald Trump, there has been a significant shift towards attitudes of entitlement and traditional gender roles (Hall, 2019, p. 108), even resulting in a very close call for the ban of abortion in the state of Georgia, which would have infringed on female reproductive rights (TIME Magazine, 2020). Toxic masculinity is a dangerous consequence of patriarchal ideals and morals, and has the potential to seriously endanger not only women and members of the LGBTQ+ community, but cisgendered heterosexual men as well.

\section{How the Concepts of Gender Roles and Toxic Masculinity Translate into Heterosexual Relationship Problems}

Now that the literature has been overviewed and the concepts of gender roles and toxic masculinity have been fleshed out, this section of the paper will explore how these concepts manifest themselves in the behaviours of heterosexual couples. In particular, the behaviours that will be examined are practice of coercive control, as well as physical and sexual violence; each of these behaviours often has roots in the issues of gender norms and toxic masculinity on both sides of the gender spectrum. As demonstrated by the previously mentioned literature, both men and women can become guilty of these behaviours, and all genders can also be guilty of exhibiting toxic masculinity, an adherence to outdated gender roles, or a combination of both. With this in mind, we must observe and analyze the relationship behaviours of heterosexual couples in relation to the adherence to traditional gender roles as well as the exhibition of toxic masculinity.

Before diving into the individual maladaptive behaviours often present in heterosexual relationships, we should first explore and comment on how women can exhibit traits of toxic masculinity and adherence to outdated gender roles. Although there is little academic information on the presence of toxic masculinity in women, we can see examples of this in the Abbot et al. article when the female participants discuss their female peers as well as their dating habits; as 
mentioned previously, many of the girls in the study upheld double standards towards dating when they mentioned that their dating rituals do not include asking boys out on dates, and that boys should always be the ones to ask girls on dates (Abbot et al., 2020, p. 7). Furthermore, the girls expressed instances of toxic masculinity when they described their female peers as competitors for boy's affection who "try their best to have him" (Abbot et al., 2020, p. 6), even stating that "some girls (...) don't have morals" (Abbot et al., 2020, p. 6), as well as when they justified the idea of a male partner deciding that his girlfriend's clothes are inappropriate (Abbot et al., 2020, p. 11). Why women exhibit traits of toxic masculinity can be explained with the concept of internalized male gaze; as described by Holland et al., women with internalized male gaze live feminine identities, but they do so in relation to the male audience, "measuring themselves through the gaze of the "male-in-the-head"" (Holland et al., 1998, p. 11). In other words, women have been socialized to view themselves and others through a male perspective, thus assigning value to themselves and others in conjunction to what this male gaze dictates. With this concept of women's internalized male gaze contributing to actions of toxic masculinity in mind, we must now observe how these specific concepts interact with one another in order to form certain behaviours within heterosexual relationships.

Previous literature states that coercive control is a tool used in intimate relationships to establish dominance over one's partner (Jones, 2020, p. 1300). Coercive control has been defined as the nonphysical tactics used by abusers to maintain power and control over their partner often through the use of intimidation, threats, surveillance, isolation, financial control, and control over the partner's daily activities (Jones, 2020, p. 1300). Most often, coercive control is used in conjunction with physical or sexual violence in order to establish an unequal power dynamic between partners so that one partner may exert their will over the other as they please, with this dominance being a facet of the gender roles that have been discussed thus far (Cook \& Goodman, 2006, p. 1053). As previously stated, traditional gender roles dictated that husbands held dominance over their wives, which can be applied to this concept of coercive control in the idea that men who practice this abusive behaviour are hoping to establish the dominance over their wives that they were promised through the socialization of traditional gender roles, as well as to maintain their male privilege (Jones, 2020, p. 1301). Conversely, women may perhaps use this method of control in order to gain the dominance they feel they are lacking within their relationship. However, it is difficult to verify this claim due to the fact that there is little research on female perpetrators of coercive control; this is due to the fact that males are overwhelmingly more likely to engage in practices of coercive control because of their advantage in the patriarchal structure of society (Hayes \& Kopp, 2019, p. 296). However, what should be noted is that according to a study by Kaisan and Painter (1992) which studied male and female college students who had been victims of abuse, male participants reported experiencing higher levels of psychological abuse than the females (Kaisan \& Painter, 1992, as mentioned in McHugh et al., 2013). Furthermore, another study concluded that females are more likely to engage in psychological abuse through monitoring and manipulation behaviours, whereas men are more likely to treat their female partners as inferior due to the aforementioned gender biases (Follingstad, 2007, as mentioned in McHugh et al., 2013). Interestingly, scholars have found that women's use of coercive control and psychological abuse may not stem from gender roles, but they often weaponize gender norms and stereotypes in order to emasculate the male partners 
(McHugh et al., 2013, p. 176). What is proven here is that instances of coercive control are most often caused by instances of toxic masculinity as well as the adherence to outdated gender norms which then trigger abusive behaviours that are used in order to establish dominance within the heterosexual relationship; not only is coercive control used a result of toxic masculinity as well as adherence to gender norms, this form of psychological violence itself employs the concepts of toxic masculinity and gender roles in order to weaponize them.

Physical and sexual abuse in heterosexual relationships are notoriously common (Jeffrey \& Barata, 2019, p. 85; Hayes \& Kopp, 2020, p. 294); in particular, sexual violence within heterosexual relationships is most often accomplished through verbal and psychological pressure (Jeffrey \& Barata, 2019, p. 86), while physical violence often occurs in two types, intimate terrorism and situational couple violence (Jones, 2020, p. 1300). These two types of physical violence can be defined as follows; intimate terrorism is described as physical violence embedded in a pattern of behaviours which are often used by perpetrators to exert dominance over victims, while situational couple violence often takes the form of individual arguments in which one or both partners physically harm the other (Jones, 2020, p. 1300). Sexual violence within committed heterosexual relationships on the other hand, often occurs as a result of coercive interaction in which there are expectations to have sex (Jeffrey \& Barata, 2019, p. 86). Furthermore, one should note the fact that as a relationship progresses, men's violations of sexual refusal often become more acceptable while women's refusal to have sex becomes less acceptable (Jeffrey \& Barata, 2019 , p. 87). However, males are not the only perpetrators of sexual assault; according to an article by Mulder et al. (2019), 1.7\% of men have reported being raped, while $23.4 \%$ of men have reported experiencing some other form of sexual assault or harassment (Mulder et al., 2019, p. 13). Similar to coercive control, both sexual and physical violence are often used as a way to exert dominance over one's partner, therefore, just like with coercive control the reasons behind many situations of physical and sexual abuse stem from the structural inequality that has resulted in gender norms and toxic masculinity. What's more, the Mulder et al. article observes the gendering of sexual violence narratives; they argue that sexual assault in the widespread general frame has been labelled as feminine, therefore worsening the experiences of male sexual violence victims (Mulder et al., 2019, p. 14). Just like with coercive control, both physical and sexual violence have been classified by the ideals and values that are present in toxic masculinity and traditional gender roles, demonstrating the hypothesis that this research paper had originally set out.

\section{Conclusion}

This research paper set out to understand just how the concepts of toxic masculinity and gender roles contributed to negative or abusive heterosexual relationship behaviours. The present paper explored the different ways in which toxic masculinity and gender roles operate within society as well as how they originated in order to apply these concepts to modern issues in heterosexual relationships. By exploring the previous literature on each of these topics individually, this paper accomplished what it had set out to do; each of the previously mentioned pieces of literature contributed valuable information as to the ways in which gender roles and toxic masculinity contribute to heterosexual relationship problems. What this paper demonstrated was 
the fact that both toxic masculinity and gender norms find their origin in religious institutions which dominated populations for a certain period of time; these religious institutions and the moralities that they are associated with have contributed to both the micro-level interactions that heterosexual couples have, as well as macro-level policies which further endanger the victims of these moralities, while simultaneously upholding these same paternalistic values. Furthermore, this research paper found that the concepts of gender roles and toxic masculinity victimize both men and women; within heterosexual relationships, men and women are both capable of inflicting coercive control and physical or sexual abuse, which demonstrates the widespread reach that toxic masculinity and adherence to gender roles have. Women's internalization of the male gaze, paired with male's structural advantage over females within patriarchal societies are the key factors in many heterosexual relationships which are plagued with coercive control, physical abuse, sexual abuse, or any combination of the three. It is imperative for sociologists to continue research into both the micro- and macro-level implications of widespread toxic masculinity as well as adherence to outdated gender roles in order to diminish the consequences of these societal ills. In order to finally achieve a society which is no longer plagued by toxic masculinities or compromising gender roles which both encourage the subjugation of men and women, we must first recognize and acknowledge the underlying yet overwhelming presence of these concepts in our everyday lives. 


\section{References}

Abbot, K., Weckesser, A., \& Egan, H. (2020). 'Everyone knows someone in an unhealthy relationship': Young people's talk about intimate heterosexual relationships in England. Sex Education, pp,1-16. DOI: 10.1080/14681811.2020.1801407

Carlisle, M. (2020, July 14). Federal judge blocks Georgia's controversial law banning most abortions after 6 weeks. TIME. Retrieved from https://time.com/5866714/georgiaheartbeat-abortion-law-ban/

Connell, R. W., \& Messerschmidt, J. W. (2005). Hegemonic masculinity: Rethinking the concept. Gender and Society, 19(6), pp. 829-859. DOI: 10.1177/0891243205278639

Cook, S. L., \& Goodman, L. A. (2006). Beyond frequency and severity: Development and validation of the brief coercion and conflict scales. Violence Against Women, 12(11), pp. 1050-1072. DOI: 10.1177/1077801206293333

Coon Sells, T. G., \& Ganong, L. (2016). Emerging adults' expectations and preferences for gender role arrangements in long-term heterosexual relationships. Sex Roles, 76, pp. 125 137. DOI: $10.1007 / \mathrm{s} 11199-016-0658-2$

Emihovich, C. A., Gaier, E. L., \& Cronin, N. C. (1984). Sex-role expectations changes by fathers for their sons. Sex Roles, 11(9, 10), pp. 861-868. Accessed from http://web.b.ebscohost.com.ezproxy.macewan.ca/ehost/pdfviewer/pdfviewer?vid=0\&sid= 1d9eff62-4194-4b0e-bc2c-4ebef80a73fa\%40pdc-v-sessmgr01

Gidney, C. (2007). Dating and gating: The moral regulation of men and women at Victoria and University Colleges, University of Toronto, 1920-60. Journal of Canadian Studies, 41(2), pp. 138-160, 221. DOI: https://doi.org/10.3138/jcs.41.2.138

Hall, C. M. (2019). Merging efforts: The intersections of domestic violence intervention, men, and masculinities. Men and Masculinities, 22(1), pp. 104-112. DOI: $10.1177 / 1097184 X 18805565$

Hayes, B. E., \& Kopp, P. M. (2019). Gender differences in the effect of past year victimization on self-reported physical and mental health: Findings from the 2010 national intimate partner and sexual violence survey. American Journal of Criminal Justice, 45, pp. 293 312. DOI: $10.1007 / \mathrm{s} 12103-019-09510-7$

Holland, J., Ramazanoglu, C., Sharpe, S., \& Thomson, R. (1998). The Male in the head: Young people, heterosexuality and power. The Tufnell Press.

Hoskin, R. A. (2019). Femmephobia: The role of anti-femininity and gender policing in LGBTQ+ people's experiences of discrimination. Sex Roles, 81, pp. 686-703. DOI: 10.1007/s11199-019-01021-3

Jones, M. S. (2020). Exploring coercive control, PTSD, and the use of physical violence in the pre-prison heterosexual relationships of incarcerated women. Criminal Justice and Behaviour, 47(10), pp. 1299-1318. DOI: 10.1177/0093854820920661

McHugh, M. C., Rakowski, S., \& Swiderski, C. (2013). Men's experience of psychological abuse: Conceptualization and measurement issues. Sex Roles, 69, pp. 168-181. DOI: 10.1007/s11199-013-0274-3

Mulder, E., Pemberton, A., Vingerhoets, A. J. J. M. (2019) The feminizing effect of sexual violence in third-party perceptions of male and female victims. Sex Roles, 82, pp. 13-27. DOI: $10.1007 / \mathrm{s} 11199-019-01036-\mathrm{w}$ 
Paynter, A., \& Leaper, C. (2016). Heterosexual dating double standards in undergraduate women and men. Sex Roles, 75, pp. 393-406. DOI 10.1007/s11199-016-0628-8

Waling, A. (2019). Problematising 'toxic' and 'healthy' masculinity for addressing gender Inequalities. Australian Feminist Studies, 34(101), pp. 362-375. DOI: 10.1080/08164649.2019.1679021

Wilchins, R. (2019). Gender Norms and intersectionality: Connecting race, class and gender. Rowman \& Littlefield Publishers. 